\title{
The view of teachers on bullying and implications for nursing
}

\author{
O OLHAR DE PROFESSORES SOBRE O BULLYING E IMPLICAÇÕES PARA AATUAÇÃO \\ DA ENFERMAGEM
}

\section{LA MIRADA DE LOS PROFESORES SOBRE EL BULLYING Y LAS IMPLICACIONES PARA LAACTUACIÓN LA ENFERMERÍA}

\section{Marta Angélica lossi Silva ${ }^{1}$, Jorge Luiz da Silva ${ }^{2}$, Beatriz Oliveira Pereira ${ }^{3}$, Wanderlei Abadio de Oliveira ${ }^{4}$, Marcelo Medeiros ${ }^{5}$}

\begin{abstract}
Objective: To understand school bullying from the perspective of teachers and reflect about the possible actions of the health area when coping with it. The guidelines of the School Health Program of the Ministries of Health and Education were used to reach that purpose. Method: A qualitative study carried out with teachers of a public school in Minas Gerais. Focus groups were used to collect data and the empirical material was decoded from thematic analysis of content, resulting in an analytical category: conceptions and experiences of teachers on bullying. Results: Specific perceptions about the phenomenon and the use of ineffective intervention resources were identified. In the interpretive plan were problematized the health and nursing contributions with resizing the interventions and the continuing training process of teachers. Conclusion: The results point to the construction of intersectoral practices for coping with bullying.
\end{abstract}

\section{RESUMO}

Objetivo: Compreender o bullying escolar, na perspectiva dos professores, e refletir sobre as possíveis ações da área da saúde em seu enfrentamento. Para tanto, tomaram-se por base as diretrizes do Programa Saúde na Escola, dos Ministérios da Saúde e da Educação. Método: Estudo de caso qualitativo, realizado com professores de uma escola pública de Minas Gerais. Foram utilizados grupos focais na coleta de dados e o material empírico foi decodificado a partir de técnica de análise temática de conteúdo, resultando em uma categoria analítica: concepções e experiências de professores diante do bullying. Resultados: Foram identificadas percepções pontuais sobre o fenômeno e utilização de recursos de intervenção pouco eficazes. No plano interpretativo, problematizaram-se as contribuições da saúde e da enfermagem no redimensionamento das intervenções e no processo de formação continuada dos professores. Conclusão: Os resultados apontam para a construção de práticas intersetoriais para o enfrentamento do bullying.

\section{RESUMEN}

Objetivo: Comprender el bullying escolar desde la perspectiva de los profesores, y reflexionar sobre las posibles acciones del área de salud en su enfrentamiento. Tomando como base los lineamientos del Programa de Salud Escolar, de los Ministerios de Salud y de Educación. Método: Estudio de caso cualitativo realizado con los profesores de una escuela pública en Minas Gerais. Para la recolección de datos se utilizaron grupos focales y el material empírico fue decodificado a partir de la técnica de análisis temático de contenido, dando lugar a una categoría analítica: concepciones y experiencias de los profesores sobre el acoso escolar. Resultados: Se identificaron percepciones específicas sobre el fenómeno y la utilización de recursos ineficaces de intervención. En el plano interpretativo, se problematizaron las contribuciones de la salud y de la enfermería en el redimensionamiento de las intervenciones y en el proceso de formación continua de los profesores. Conclusión: Los resultados apuntan a la construcción de prácticas intersectoriales para el enfrentamiento del bullying.

DESCRIPTORES
Violencia
Escolas
Estudiantes
Salud escolar
Enfermería

\section{DESCRIPTORS}

Violence

Schools

Students

School health

Nursing

\author{
DESCRITORES \\ Violência \\ Escolas \\ Estudantes \\ Saúde escolar \\ Enfermagem \\ Promoção da saúde
}




\section{INTRODUCTION}

Bullying is conceptualized as a relationship problem, characterized by violent behavior for assaulting or harassing someone, and by imbalance of power between the involved parties (victims and offenders) ${ }^{(1-2)}$. It is a complex and multidetermined phenomenon in all sociocultural realities, distinguishing itself as a specific form of aggressive behavior among children / adolescents and their peers. It is considered a public health problem ${ }^{(3-4)}$, because of its high prevalence, estimated at about $30 \%$ in Brazil and other countries, as well as due to the harmful consequences it brings to the subjects involved in the practice ${ }^{(5-6)}$.

Regarding its nature and content, bullying can assume more traditional forms, which include aggressive behavior of physical nature (punching, kicking, shoving, etc.), verbal (gossip, insults, nicknames, etc.) and psychological (threats, insults and blackmail). Newer forms such as cyberbullying, online bullying and by phone have been used to spread slanderous or libelous posts. It can also be experienced directly (aggressions to victims in their presence) or indirectly (that usually happen in the absence of the victim, for example, spreading gossip, spoiling belongings, among others) $)^{(1-2,7)}$.

Evidence from scientific literature on the subject suggests that the dynamics of school bullying includes not only the victims or perpetrators, but also brings indirectly in its mechanism the classmates, teachers, other employees of the school, parents and the community ${ }^{(8-10)}$. That points to extend the range of its effects that affect not only the students directly involved, but also all the subjects with whom they relate, regardless of the strength or intensity of the practiced aggression.

In this sense, research on bullying has scientific and social relevance, due to its potential of changing the relationships affected by it, and by pointing out the possibilities of intervention related to education, as well as individual and collective health. Perhaps for those reasons it has become an increasingly valued theme by research and interventions in the areas of education and health ${ }^{(2-3,9-10)}$. From these researches and interventions have emerged important intersectoral strategies for coping with bullying, at the same time that are discussed the role of professionals acting in them (teachers, pedagogues, psychologists, nurses, doctors, etc.).

In Brazil, an example is the School Health Program, created in 2007 by the Ministries of Health and Education. This program is resultant of a dense work of national policies in the areas of education and health. It has the goal of expanding the access of students served by public schools across the country to specific health actions, with a prospect of management and operationalization by the primary care through the work of professionals who compose it (nurses, doctors and caregivers) ${ }^{(11)}$.
In its motto, the program recommends the professionals to consider the school as a place for health care. However, without losing sight of the peculiar characteristics of educational institutions, aimed at the development of teaching-learning processes and of students training to act in social life, based on the combined efforts of educators and other members of the school community. The intention is that the interface between health and education allows establishing many agreements between the development of healthy habits and lifestyle practices, and the educational process of students, resulting in benefits for the whole society (school, family and community) ${ }^{(11)}$. Thus, health in the school and of the school is an interdisciplinary work alternative with concrete possibilities of interventions that may be successful and efficient.

In the operationalization of the program at the school, the role played by the school staff, especially by teachers, is essential to the planning and execution of proposals. There is even a recommendation to take

as a starting point, 'what they know' and 'what they can do', developing in each individual the ability to interpret the daily life and act to incorporate appropriate attitudes and/ or behaviors (...) in the performance of their duties ${ }^{(11)}$.

In situations of bullying, the teachers themselves perceive this phenomenon as an obstacle to accomplish healthy environments that are able to contribute with putting into practice a culture of nonviolence ${ }^{(9-10)}$.

In this scenario, nursing plays an important role, to the extent that this area provides response opportunities to the processes of development or adaptation through which pass the students, teachers and the school community as a whole. It is part of the nursing's responsibility as an area of knowledge and as a profession, to contribute with promoting processes of autonomy, health and living with the differences, identifying risk signs, behaviors and modalities of involvement of students in bullying situations, as well as how these situations impact in them in terms of learning, training, health and quality of life. Given its characteristics of training and insertion in different contexts, the nursing may favor the alert to families on the consequences of this phenomenon, guiding them for intervention, as well as encouraging and supporting schools in the implementation of programs for prevention and reduction of violence ${ }^{(12-15)}$.

Internationally, these points of view are already adopted, especially with the inclusion of nurses in the school context. In these cases, with all intervention possibilities for nurses in face of the school violence phenomenon, the literature shows how important is that nurses act together with teachers, to the extent that these professionals play a key role in identifying and intervening in bullying among students. Recent studies indicate that the level of commitment of the teacher in carrying out interventions is an essential component to the success of preventing and combating school violence ${ }^{(12,16)}$.
The view of teachers on bullying and implications for nursing Silva MAI, Silva JL, Pereira BO, Oliveira WA, Medeiros $M$ 
However, the role of nurses in schools, in relation to preventing and coping with bullying, is composed of actions directed exclusively to students, especially to victims, by techniques of dialogue/reflection, role playing, development of coping skills ${ }^{(17-18)}$, among others. Nursing interventions that consider the figure of teachers as equally critical for the control and eradication of violence attitudes in class are rare ${ }^{(12)}$.

Based on these considerations, focusing on the relevance of the teachers' role in reducing incidents of violence in the classroom, this study aimed to understand bullying in the school context, from the perception of elementary school teachers, as well as reflecting on possible actions for coping with it, related to the health area, especially in relation to nursing.

\section{METHOD}

This is a case study of a qualitative nature. The case study is a means of organizing social data, using strategies of qualitative investigation to map, describe and analyze the context, relations and perceptions about the situation, phenomenon or episode in question ${ }^{(19)}$.

The study was carried out in a public school in a city in the countryside of the state of Minas Gerais, selected for convenience because it constituted a field of internship, and of research in health and education at a local university. Teachers of the $6^{\text {th }}$ grade of elementary school participated in the survey and this was the inclusion criteria for participating in the study. This period of schooling was chosen due to studies ${ }^{(5,20)}$ indicating the existence of vulnerability peaks to bullying practices during transitions in education (cycle changes between the $5^{\text {th }}$ and the $6^{\text {th }}$ grade of elementary school and between the $9^{\text {th }}$ year of elementary school and the $1^{\text {st }}$ year of high school), according to the national and international literature $^{(2,5)}$. Moreover, for most students the transition to the $6^{\text {th }}$ year coincides with the adolescent period (characterized by biological transformations, of intelligence, character and personality), in which increase the probability of displaying risk behavior and the exposure to violence ${ }^{(2,11)}$.

Thus, 12 teachers from four $6^{\text {th }}$ grade classes of the investigated school were invited to participate in the study. However, only half of them $(n=6)$ agreed to cooperate with the research under the requirement that meetings were carried out during the class period, since they all worked double or triple shifts. The composition of the group of participants was as follows: four were female and two were male. The average age of teachers was 40.5 years and the average teaching time was 10.8 years. The initial training of the participants were the following courses: Biology, Philosophy, History, Mathematics and two in Letters. All worked double shifts, teaching at two or three schools.

For data collection was used the focus group technique to check the position taken by teachers on the practices of violence among adolescents, the adopted attitudes and the criteria and references on which they based their interventions. Three meetings were held, following a script with guiding questions organized in three blocks, namely: 1) knowledge of teachers about bullying; 2) forms of identifying violence during classes, and its distinction from other behaviors such as indiscipline, for example; 3 ) behaviors adopted in face of the identification of bullying situations among students. These blocks favored movements of discussion and debate in the group.

The focus group is a nondirective qualitative research technique, in which the result aims at understanding and controlling the discussion of a group of people about a certain topic. In this technique, the most important is the interaction that takes place in the group. The facilitator of the discussion should establish and facilitate it, and not hold a group interview ${ }^{(21-22)}$. The technique can be used to search for a specific object and at the same time, for the training of those involved in it.

The meetings of the focus group were recorded, transcribed, and then analyzed. Data analysis followed the guidelines of content analysis in its thematic, in accordance with the steps of: a) pre-analysis, b) exploration of the material, c) treatment of results and d) interpretation ${ }^{(19)}$. In this sense, after a thorough reading of the material, considering the data together, from the frequency of the segmented and comparable units of meaning, were designed thematic units present in the decoding of meetings, and the following analytical category was identified: Conceptions and experiences of teachers in face of bullying. Thus, was prepared an interpretive synthesis able to relating the categorized topics with the objective and proposal of the research, and using the guidelines of the School Health Program as reference.

The research project was submitted to a Committee of Ethics in Research under protocol number 0011.0.227.00010 , and approved under registration number 031-2010. For confidentiality reasons and to preserve the identity of participants, their names were coded T for Teacher, followed by a number assigned to the participant (participant 1 - T1, participant 2 - T2, for example).

\section{RESULTS}

\section{Conceptions and experiences of teachers in face of bul- lying}

From group focus discussions were obtained the following definitions of bullying:

\begin{abstract}
Bullying is embarrassment, violence, aggression (T5); humiliation (T3); it's when a group name calls you, picks on you (P2); mocking, picking on, attacking, harassing, ridiculing (P1); pranks (P6); it's embarrassment at an emotional level, physical level, and even spiritual level (P4).
\end{abstract}

Other key characteristics for the definition were identified, for example, the existence of a power imbalance between bullies and victims: 
they never bully someone who is as strong as they are, you can see (T1); as well as the presence of an intentional character in the aggressions: (...) they provoke because they really want to, not because they don't know what bullying is, they don't need to know what bullying is. The thing is, what's behind it, and what's behind is that they want to attack, they want to embarrass, humiliate, then it's bullying (T4).

However, teachers demonstrated ignorance regarding some aspects, such as the lack of a clear motivation for the attacks, their repetition, and the fact that most of the time they happen far from the adults. Therefore, it is evident that teachers participating in the study were aware of the bullying, but incompletely, making it difficult to identify it in the classroom and differentiate it from other recurrent behavior in the school environment, such as jokes and lack of discipline, as reported by participant T2:

I have a hard time drawing the line between bullying and a bad joke (...). What I have to notice is what is bullying and what is not.

In contrast, other teachers contend it is not only the lack of specific knowledge that hinders the identification and intervention in school violence, but also issues related to the way teaching is organized and the institutional demands directed to the work they carry out.

I work fifty minutes of a twenty-four hour day, in a week that has, who knows, how many hours (...) (T4).

And another thing is, we have a content that is demanded in evaluations, sometimes, it's not always and not every class, that you happen to have the time to actually stop. (T3).

Redistribution of the hour load from the sixth year, with the fragmentation of education in different subjects taught by different teachers, and the requirements for quality of learning, are seen by participants as factors that complicate the pedagogical routine, negatively interfering in how they relate with students and intervene in bullying situations. In this respect, a teacher made the following comment:

It's possible to identify many things exactly for being working on values, but when I identify, depends on the day, the hour, on my mood and my creativity (T4).

Another fact to be highlighted is the average years of work experience showed by the teachers ( 10.8 years). In other words, their accumulated experience has proven to have little determination on the authority they demonstrate in relation to bullying, as well as on how they identify it and intervene. In general, they demonstrated to be able to identify specific and occasional situations:

pranks (T3); nicknames (T2 and T4); criticism (T5); fights (T2); mocking, kicking, punching (T6); picking on, comments, criticisms (T4).
Another side of the problem presented by teachers refers to the feeling of unpreparedness to deal with situations of violence in the school context:

I think we should have to study psychology first, and then the licenciature (T3).

The result of this context is that feelings of frustration arise, as they are faced with difficult and multifaceted situations for which they feel or actually are little prepared to tackle.

Teachers recognize that situations of school violence are complex and require more comprehensive and coordinated interventions, but find it difficult to come up with the necessary solutions, as suggested by the position below:

(...) the solution to deal with this is another crystal, with other parts, and we often have a repetitive attitude. (...) That is why there may be so much, because we are not being creative to interfere (T4).

Regarding the strategies to cope with the matter, in general, study participants use the dialogue or shift the responsibility of intervention for the school administration.

Usually I also show the side of reflection, of putting the student in place of the one being assaulted, to see if he/ she notices the size of his/her aggression, if he/she would like to be in the same place (T3). I talk to them about situations that happened in developed countries, as in the United States when those boys started shooting in the entire school (T1). I have already caught two boys fighting and took them to the headmaster (T2).

It was also identified that interventions occur to a greater or lesser extent, depending on which students are involved in the harassment. When those considered problematic assume the position of victim, teachers usually have the tendency of omitting themselves. Or just superficially call the attention and go back to class:

(...) in those cases that bother me much I stop, but sometimes, as T1 said herself, inside the small groups that exchange many verbal aggressions among themselves, I usually only call the attention and get back to class (T5). Oh, now I'm wrong because I say: never mind, let's take care of our task? (T2).

The material found in the focus groups points to deficiencies in teacher training. It also shows the need for interventions by multidisciplinary teams able to assist in coping with bullying and point to the necessary interface and partnership with the family.

What is beyond our competence, we usually direct to the supervisors, headmaster (T3). I think the school should have a multidisciplinary team to work these issues, not only with teachers but also with students. I really miss that, because we are not prepared to handle this type of problem: psychological, social (T5).

\section{Rev Esc Enferm USP \\ 2014; 48(4):723-30 \\ www.ee.usp.br/reeusp/}

The view of teachers on bullying and implications for nursing Silva MAI, Silva JL, Pereira BO, Oliveira WA, Medeiros $M$ 


\section{DISCUSSION}

Considering the strategic importance of the role of nurses in health care for school individuals, and in the light of the need for effective solutions to bullying situations, the scarcity of interventions by nurses aimed at working the school community in an interdisciplinary and intersectoral manner, involving students, teachers, family, community and health services ${ }^{(12)}$, and the gaps and needs for actions and bullying prevention programs recognized by the teachers who participated in this study, are problematized the potentialities of intersectoral actions and the implications and contributions of other areas, such as health, for example, in addressing this problematic. Then, the School Health Program emerges as a possibility for helping teachers because it has the proposition of constructing measures of education and health promotion, with the view of preventing violence such as bullying.

In general, the understanding of teachers about the phenomenon coincides with some aspects identified in the literature concerning the nature of aggression (physical, verbal and psychological), as it is understood as negative behaviors, intimidation, insults, harassment, exclusion and discrimination of all kinds that cause feelings of inferiority in the victims, and in general, contribute to the development of psychological and social disorders ${ }^{(1-5,9,13,15)}$. Other essential characteristics to the definition have been identified, such as the existence of an imbalance of power between victims and aggressors ${ }^{(1-2)}$.

Teachers summarize a difficulty in the teacher training process, often coupled with the lack of meaningful and necessary content for the practical application. In this sense, it is noticeable that the education system has optimized the topic of bullying and taken it to the agendas of discussion in schools, but not always the training activities have offered quality or meet the needs of teachers, which does not help to improve the situation ${ }^{(22)}$.

This can be considered worrisome because several studies indicate that the majority of teachers have difficulty in identifying the aggression practiced by the students, especially the more subtle, mainly due to weaknesses in the initial training for teachers and the complexity of violence situations in the interaction between students ${ }^{(10,12,15)}$. However, in many identified cases, teachers are required to adopt measures to deal with the phenomenon in question, in its different manifestations, though not always they are or feel prepared to do so.

It should be emphasized that the accurate identification, which supports effective interventions, does not occur due to lack of more complete knowledge on the subject, which prevents that more subtle situations or nuances of bullying are recognized, hence being neglected, limiting the focus to physical and verbal aggression of more evident manifestation ${ }^{(9-10)}$. These data suggest that experience alone is not enough, if not intertwined or correlated to training and/or professional development that allows subsidizing consistent technical actions appropriate to the context and specificities of situations.

Regarding strategies for coping with the matter, in general, the study participants have discussions about the act with the aggressors and the class, or refer the situation to the school administration, most times, without considering the participation of the students' families in problem solving, or in articulated interventions with other sectors of the community, aimed at intervention and prevention $^{(2,9-10,23-24)}$. It is noticeable that aspects of personal nature and the stress experienced at work also affect how teachers position themselves in face of violence ${ }^{(9)}$.

It is concluded that the reflections in the classroom and referrals to the school board are perceived by the literature as more reactionary measures, and little preventive in relation to bullying. As this is a multifaceted and complex phenomenon, most effective preventive actions require using equally complex methods that reach the whole school and also from a preventive perspective, in a way that activities have indirect approaches, are focused on avoiding the problem and not restricted to post-fact measures ${ }^{(2,9-10,12)}$.

Activities that reserve time to discuss the topic and forms of prevention, which includes establishing rules of behavior for the classroom and school spaces, guided by the construction of more positive models of social relationship and interaction, can reframe the school and contribute to a secure environment. All those aspects favor the culture of non-violence ${ }^{(24-27)}$.

Therefore, from the research data was found the importance of encouraging teachers to develop multiple strategies to respond to bullying, resorting to the ones in which the intensity depends on the chronicity and/ or the nature of the victimization/intimidation. In other words, teachers can modify their interventions according to some variables, namely: a) if that is the first time the violence occurred, $b$ ) if it engaged other children or $c$ ) the nature of the aggression was physical, verbal or psychological. Clearly, for this purpose, training and support actions are needed in order to effectively deal with bullying after its identification.

In face of these kinds of demands, the health teams in primary care have been encouraged to work within schools to minimize aggressions or assist in constructing responses to the problem of violence and bullying in these institutions. The most tangible example of these intersectoral efforts is the School Health Program, designed as a potential policy to assist in putting into practice the principles of the Unified Health System (SUS - Sistema Único de Saúde) and ensuring conditions for the healthy development of children and adolescents ${ }^{(11)}$. 
The model adopted by the School Health Program recognizes health as being multifactorial and crossed by social and environmental processes, while it sees that school failure and learning difficulties are also related to psychosocial issues as well as to health-related determinants. Then, the school is understood as a privileged place of relationships and a space for developing health actions that prioritize the creation of healthy habits, positive relationships, emancipation and building of personal autonomy ${ }^{(11-12)}$

The answers to the knowledge and control of harms to health and bullying are encouraged from the understanding of an intersectoral action that appreciates the relationship between the actors of primary care and the school, in the territories where the life and health of children and adolescents are produced. In this scenario, the health team professionals are encouraged to enter the school for mediating actions of health prevention and promotion. Thus, the anti-bullying interventions would not be assigned exclusively to schools, but considered of such complexity that requires the collaboration of other protagonists ${ }^{(12-15,28)}$.

In this sense, the health intervention in school gathers its professionals and proposes that their functions are redesigned. Specifically in the case of nursing, professional assignments will continue to be required to operate at this complexity level of care, but other perspectives will be incorporated once the nursing professional should perform assessments and interventions that will need to involve the whole team. Thus, it appears that the actions of these teams need the support of the uniformity of discourse, and the understanding of the reality of the territories, aimed at contributing to the development of healthy environments, related to the proposal of coping with bullying and building a culture of non-violence ${ }^{(3,12)}$.

In relation to the scope of the profession, nursing may go beyond the dimension of care and expand to various contexts, contributing to accomplishing or implementing public policies, intersectoral and comprehensive actions. This type of intervention can strengthen the understanding of teachers, assisting them in identifying complex situations and not just in those specific and/or occasional. This dimension also favors strategies to deal with the feeling of unpreparedness manifested by them in face of situations of violence in the school context, to the extent that nurses can articulate actions and resize responses to bullying, because they can involve other actors of the community in the coping process, such as family and other social equipments ${ }^{(12-15,28)}$.

From another perspective, the role of nurses can support a better preparation of teachers and other education and health professionals to identify bullying situations, even when the time and contact with students is reduced or challenged by pedagogical issues. Thus, the perception of teachers about the shortfall in the training process can be combined with the performance possibilities of health in relation to continuing education, already common in the area, and widely encouraged in education. Hence, the contributions of other professionals and areas for expanding this process of continuing education are so significant and valued by intersectoral policies ${ }^{(11-15)}$.

From the analysis of the data, was reached the conclusion that in the scenarios of bullying, another possibility for nursing action is related to the possibility of research in health, considering the support of comprehensions and interventions on this social phenomenon of significant impact on the health of children and adolescents. These studies assume the character of intervention, because they take to school the health professionals involved with the issue and willing to assist in knowledge about bullying, helping with activities offered by schools in relation to preventing, minimizing and coping with the issue.

\section{CONCLUSION}

The study results indicate the understanding of teachers about school violence and provide support for the planning and implementation of intersectoral intervention activities related to bullying, since it manifests and is influenced by multiple contexts. Thus, in the School Health Program operation, nurses can work directly in schools in order to diagnose this problem, and identify and implement specific interventions for the education community, victims, offenders, families and the community in general through arrangements with community health workers and programs developed in primary care.

The primary care professionals, especially nurses, can still intervene in this scenario in order to identify situations that may or may not be related to the manifestation of bullying, such as the dynamic and relations in the family, for example. In primary care, these professionals also nurture the organization of projects to reduce aggressive behavior, for conflict resolution and for developing social skills, in addition to working with families, which gains strength with proposals of non-violence culture and policies in the area.

Integrated professional actions can promote schoolbased interventions that incorporate broader contextual aspects, considering characteristics of individuals, family, school and the community, which are related to manifestations of bullying in the school. It is important that diagnosis, interventions and prevention initiatives, as well as teacher training, take into account the multifactorial processes that originate the violent behavior. Finally, it is suggested that further studies are carried out to help understanding the issues and nuances of bullying and the possibilities of intersectoral intervention, enabling greater visibility and the consequent discussion of the phenomenon and the potentialities for its minimization.
The view of teachers on bullying and implications for nursing Silva MAI, Silva JL, Pereira BO, Oliveira WA, Medeiros $M$ 
1. Olweus D. Bufllying at school and later criminality: findings from three Swedish community samples of males. Crim Behav Ment Health. 2011;21(2):151-6.

2. Olweus D. School bullying: development and some important challenges. Annu Rev Clin Psychol. 2013;9(1):751-80.

3. Knous-Westfall HM, Ehrensaft MK, MacDonell KW, Cohen P. Parental intimate partner violence, parenting practices, and adolescent peer bullying: a prospective study. J Child Fam Stud. 2012;21(5):754-66.

4. Romaní F, Gutiérrez C, Lama M. Auto-reporte de agresividad escolar y factores asociados en escolares peruanos de educación secundaria. Rev Peru Epidemiol Internet]. 2011 [citado 2013 jul. 22];15(2):1-8. Disponible en: http://rpe.epiredperu. net/rpe_ediciones/2011_V15_N02/9AO_Vol15_No2_2011_ Autoreporte_bullying.pdf

5. Centro de Empreendedorismo Social e Administração em Terceiro Setor; Fundação Instituto de Administração. Bullying escolar no Brasil: relatório final [Internet]. São Paulo: CEATS/ FIA; 2010 [citado 2013 ago. 20]. Disponível em: http://escoladafamilia.fde.sp.gov.br/v2/Arquivos/pesquisa-bullying_escolar_no_brasil.pdf

6. Malta DC, Silva MAI, Mello FCM, Monteiro RA, Sardinha LMV, Crespo C, et al. Bullying in Brazilian schools: results from the National School-based Health Survey (PeNSE), 2009. Ciênc Saúde Coletiva. 2010;15(2):365-76.

7. Vlachou M, Andreou E, Botsoglou K, Didaskalou E. Bully/victim problems among preschool children: a review of current research evidence. Educ Psychol Rev. 2011;23(3):329-58.

8. Hernandez D, Floden L, Bosworth K. How safe is a school? An exploratory study comparing measures and perceptions of safety. J Sch Violence. 2010;9(4):357-74.

9. Fung ALC. Intervention for aggressive victims of school bullying in Hong Kong: A longitudinal mixed-methods study. Scand J Psychol. 2012;53(4):360-7.

10. Gázquez Linares JJ, Cangas Díaz AJ, Pérez Fuentes MC, Lucas Acién F]. Teachers' perception of school violence in a sample from three European countries. Eur J Psychol Educ. 2009;24(1):49-59.

11. Brasil. Ministério da Saúde; Secretaria de Atenção à Saúde, Departamento de Atenção Básica. Saúde na escola. Brasília; 2009. (Cadernos de Atenção Básica, n. 24).
12. Mendes CS. Preventing school violence: an evaluation of an intervention program. Rev Esc Enferm USP [Internet]. 2011 [cited 2013 jul. 25];45(3):581-8. Available from: http://www. scielo.br/pdf/reeusp/v45n3/en_v45n3a05.pdf

13. Jones SN, Waite R, Clements PT. An evolutionary concept analysis of school violence: from bullying to death. J Forensic Nurs. 2012;8(1):4-12.

14. Liu JH, Graves N. Childhood bullying: a review of constructs, concepts, and nursing implications. Public Health Nurs. 2011;28(6):556-68.

15. Perron T. Peer victimisation: strategies to decrease bullying in schools. Br J Sch Nurs. 2013;8(1):25-9.

16. Craig K, Bell D, Leschied A. Pre-service teachers' knowledge and attitudes regarding school-based bullying. Can J Educ. 2011;34(2):21-33.

17. Joronen K, Häkämies A, Astedt-Kurki P. Children's experiences of a drama programme in social and emotional learning. Scand J Caring Sci. 2011;25(4):671-8.

18. Vessey JA, O'Neill KM. Helping students with disabilities better address teasing and bullying situations: a MASNRN study. J Sch Nurs. 2011;27(2):139-48.

19. Minayo MCS. O desafio do conhecimento: pesquisa qualitativa em saúde. São Paulo: Hucitec; 2012.

20. Wynne SL, Joo H. Predictors of school victimization: individual, familial, and school factors. Crime Delinq. 2011;57(3):458-88.

21. Backes DS, Colomé JS, Erdmann RH, Lunardi VL. Grupo focal como técnica de coleta e análise de dados em pesquisas qualitativas. Mundo Saúde. 2011;35(4):438-42.

22. Hektner JM, Swenson CA. Links from teacher beliefs to peer victimization and bystander intervention tests of mediating processes. J Early Adolesc. 2011;32(4):516-36.

23. Bibou-Nakou I, Tsiantis J, Assimopoulos H, Chatzilambou P. Bullying/victimization from a family perspective: a qualitative study of secondary school students' views. Eur J Psychol Educ. 2013;28(1):53-71.

24. Hong JS, Espelage DL. A review of research on bullying and peer victimization in school: an ecological system analysis. Aggress Violent Behav. 2012;17(4):311-22.

25. Fu Q, Land KC, Lamb VL. Bullying victimization, socioeconomic status and behavioral characteristics of 12 th Graders in the United States, 1989 to 2009: repetitive trends and persistent risk differentials. Child Indic Res. 2013;6(1):1-21. 
26. Shetgiri $\mathrm{R}$, Lin $\mathrm{H}$, Flores $\mathrm{G}$. Trends in risk and protective factors for child bullying perpetration in the United States. Child Psychiatry Hum Dev. 2013;44(1):89-104.

27. Silva MAI, Pereira B, Mendonça D, Nunes B, Oliveira WA. The involvement of girls and boys with bullying: an analysis of gender differences. Int J Environ Res Public Health. 2013;10(12):6820-31.
28. Hektner JM, Swenson CA. Links from teacher beliefs to peer victimization and bystander intervention: tests of mediating processes. J Early Adolesc. 2012;32(4): 516-36. 